\title{
ANALISIS PENDAPATAN PEDAGANG MIKRO MAKANAN DAN MINUMAN DI SEKITAR MALL DINOYO CITY
}

\author{
Wahyu Dwi Nisantoro \\ PT. Bank Mandiri, Tbk. Malang \\ wahyuzant@gmail.com
}

\begin{abstract}
This study aimed to analyze the effect of variable capital, trading hours and locations micro traders to trade on the income of food and drinks around the Mall Dinoyo City Malang. In this study using primary data through direct interviews on 60 respondents micro traders of food and drinks around the Mall Dinoyo City with a list of questions that had been prepared. To achieve the goal, in this study using regression analysis ( OLS ). The results of this study indicate that the variable capital and trade locations positive and significant impact on the micro traders of food and drinks around the Mall Dinoyo. While variable trading hours do not significantly affect the income micro traders of food and drinks around the Mall Dinoyo City .
\end{abstract}

Keywords : Revenue, Business Capital, Trading Hours and Location

\begin{abstract}
Abstrak
Penelitian ini bertujuan untuk menganalisis pengaruh variabel modal, jam dagang dan lokasi berdagang terhadap pendapatan pedagang mikro makanan dan minuman di sekitar Mall Dinoyo City Kota Malang. Dalam penelitian ini menggunakan data primer melalui wawancara secara langsung pada 60 responden pedagangmikro makanan dan minuman di sekitar Mall Dinoyo City dengan daftar pertanyaan yang telah disiapkan. Untuk mencapai tujuan, dalam penelitian ini menggunakan metode analisis Regresi (OLS). Hasil penelitian ini menunjukkan bahwa variabel modal dan lokasi berdagang berpengaruh positif dan signifikan terhadap pedagangmikro makanan dan minuman di sekitar Mall Dinoyo. Sedangkan variabel jam dagang tidak berpengaruh secara signifikan terhadap pendapatan pedagangmikro makanan dan minuman di sekitar Mall Dinoyo City .
\end{abstract}

Kata kunci : Pendapatan, Modal Usaha, Jam Dagang dan Lokasi 


\section{PENDAHULUAN}

Dalam Pembangunan ekonomi pada dasarnya dicerminkan oleh terjadinya perubahan-perubahan dalam aliranbaru yang menyangkut arus pendapatan dan manfaat kepada masyarakat lokal, regional, bahkan sampai tingkat nasional. Pada sebuah pembangunan dapat mendatangkan dampak berupa manfaat yang positif atau negatif kepada masyarakat.

Lapangan kerja sektor formal menjadi prioritas utama bagi para tenaga kerja. Namun adanya krisis ekonomi yang melanda Indonesia beberapa tahun lalu, mengakibatkan banyak terjadi PHK pada sektor formal. Untuk itulah lapangan kerja sektor informal perlu dikembangkan, hal ini dapat menyediakan lapangan pekerjaan dengan penyerapan tenaga kerja secara mandiri atau dengan kata lain menjadi safety belt bagi tenaga kerja yang memasuki pasar kerja, selain itu juga menyediakan kebutuhan masyarakat golongan menengah ke bawah (Kuncoro, 2007).
Dalam pembangunan ekonomi rakyat dalam suatu negara, peran usaha mikro dalam nampak kontribusinya dapat mengatasi masalah ekonomi. Peran Usaha mikro antara lain: (1) penyerapan tenaga kerja (2) pemerataan pendapatan (3) Nilai Tambah bagi produk daerah (4) peningkatan taraf hidup.(Nurseta, 2015).

Di Indonesia peranan usaha mikro juga sering dikaitkan dengan upaya-upaya pemerintah untuk mengurangi pengangguran, mengurangi kemiskinan, dan pemerataan pendapatan. Oleh sebab itu, tidak heran jika kebijakan pengembangan Usaha Mikro di Indonesia sering dianggap secara tidak langsung sebagai kebijakan penciptaan kesempatan kerja atau kebijakan anti-kemiskinan, atau kebijakan retribusi pendapatan (Tambunan, 2012:1). Menurut Skousen (2001) pengertian pendapatan adalah sebagai berikut :"Pendapatan merupakan arus masuk atau peningkatan aktiva lainnya 
sebuah entitas atau pembentukan utang (atau sebuah kombinasi dari keduanya) dari pengantaran barang atau penghasilan barang, memberikan pelayanan atau melakukan aktivitas lain yang membentuk operasi pokok atau bentuk entitas yang terus berlangsung”.

Usaha mikro merupakan sektor industri ekonomi yang mempunyai peran penting dalam kehidupan ekonomi masyarakat. Bahkan Usaha mikro berperan sebagai penyangga ekonomi yang sudah tidak diragukan lagi, tampak dihadapan kita bahwa umumnya masyarakat bekerja dan meningkatkan taraf kehidupannya (Sartika, 2004).

Sektor perdagangan di Kota Malang semakin lama semakin meningkat dikarenakan semakin banyaknya pusat perdagangan modern. Tujuan dibangunnya pusat perdagangan modern ini diharapkan menjadi indikator kemajuan suatu daerah (Sitepu, Vol.01 - No.01). Selain itu juga menciptakan suatu lapangan pekerjaan baru bagi para masyarakat sekitar.
Keberadaan pasar modern menambah persaingan yang lebih ketat lagi dalam menjalankan usaha.. Semakin banyaknya pusat perbelanjaan di Kota Malang saat ini juga membawa dampak positif dan negatif. Dampak positifnya adalah masyarakat dapat lebih mudah beraktifitas dalam hal jual beli dan juga dapat menciptakan suatu lapangan pekerjaan baru, sedangkan dampak negatifnya yaitu arus lalu lintas menjadi tidak stabil akibat kemacetan yang terjadi di sekitar pembangunan. Faktor-faktor yang mempengaruhi produksi pedagang mikro yang berdampak pada pendapatan pedagang mikro itu sendiri, antara lain modal, jam kerja dan lokasi berdagang (Firdausa, 2013). Pedagang adalah perantara yang kegiatannya membeli barang dan menjualnya kembali tanpa merubah bentuk atas inisiatif dan tanggung jawab sendiri dengan konsumen untuk membeli dan menjualnya dalam partai kecil atau per satuan. (Sugiharsono dkk, 2000:45). Sedangkan jam kerja 
merupakan bagian dari teori ekonomi mikro, khususnya pada teori penawaran tenaga kerja yaitu tentang kesediaan individu untuk bekerja dengan harapan memperoleh penghasilan atau tidak bekerja dengan konsekuensi mengorbankan penghasilan yang seharusnya ia dapatkan. Kesediaan tenaga kerja untuk bekerja dengan jam kerja panjang ataupun pendek adalah merupakan keputusan individu (Wicaksono, 2011).

Dari studi pendahuluan diketahui bahwa Modal merupakan salah satu faktor yang menjadi kendala utama berdirinya usaha kecil.

Modal dalam suatu usaha dapat berupa modal sendiri atau modal pinjaman. Santoso (2001) mengatakan bahwa modal adalah jumlah total uang yang dikeluarkan pengusaha untuk mendirikan suatu usaha dan mengoperasikan usaha.

\section{Boediono}

mengemukakan bahwa salah satu unsur yang mempengaruhi pendapatan adalah faktor produksi yang variabel di dalamnya adalah modal. Santoso (2001) menemukan bahwa modal berpengaruh terhadap pendapatan PKL. Hal ini karena PKL yang menggunakan modal besar maka pendapatannya akan tinggi, sebaliknya yang menggunakan modal kecil akan memperoleh pendapatan yang rendah.

Menurut Bambang Riyanto (1998 : 10) Dasar-dasar Pembelanjaan Perusahaan :"Modal adalah hasil produksi yang digunakan untuk memproduksi lebih lanjut. Dalam perkembangannya kemudian modal ditekankan pada nilai, daya beli atau kekuasaan memakai atau menggunakan yang terkandung dalam barang-barang modal".

Setelah pembangunan Mall dinoyo city pedagang - pedagang mikro sekitar mengalami perubahan aktivitas perdagangan yaitu meningkatkan perdagangan atau bahkan menurunkanpendapatan pedagang dikarenakan adanya persaingan produk yang diperdagangkan antara Mall Dinoyo 
City dan pedagang Mikro di sekitar Mall Dinoyo City.

Adapun tujuan dalam penelitian ini adalah

Untuk mengetahui profil pedagang mikro makanan dan minuman di sekitar Mall Dinoyo City dan untuk mengetahui pengaruh Modal, jam dagang, dan Lokasi terhadap pendapatan pedagang mikro di sekitar Mall Dinoyo City.

\section{METODE PENELITIAN}

Lokasi yang dipilih dalam penelitian ini adalah di daerah Dinoyo Kota Malang, yaitu sekitar Mall Dinoyo City. Data yang digunakan adalah data primer, subyek yang akan dijadikan responden adalah pedagang di bidang Usaha Mikro yang berada di sekitar Mall Dinoyo City. Teknik pengumpulan data yang digunakan dalam penelitian ini adalah sebagai berikut : Penelitian Lapangan (Field Research) yaitu untuk memperoleh fakta yang terjadi di lokasi penelitian melalui kegiatan observasi, wawancara dan dokumentasi.

Analisis dalam penelitian ini menggunakan prosentase untuk mengindentifikasi pendapatan pedagang Mikro makanan dan minuman di sekitar Mall Dinoyo City. Langkah-langkah yang ditempuh dalam penggunaan teknik analisis ini adalah :

a. Membuat tabel distribusi jawaban angket modal, jam dagang, lokasi dan pendapatan

b. Menentukan skor jawaban responden dengan ketentuan skor yang telah ditetapkan

c. Menjumlahkan skor jawaban yang diperoleh dari tiap responden.

Alat analisis yang dapat digunakan adalah dengan melihat tampilan plot atau data dapat juga menggunakan uji kolmogorov smirnov (Ghozali, 2009:147). Data analisis dengan bantuan komputer program $\quad$ SPSS 16.0. Data pengambilan keputusan berdasarkan probabilitas lebih besar dari 0,05 maka data dalam penelitian berdistribusi normal. 
Teknik analisis data dalam penelitian ini adalah menggunakan metode analisis regresi, yang ditransformasikan ke logaritma berganda dengan menggunakan logaritma natural (Ln), bentuk persamaannya adalah sebagai berikut

$$
\begin{aligned}
Y \operatorname{Ln}= & \operatorname{Ln} \beta_{0}+\beta_{2} \operatorname{Ln} \beta_{x 1}+ \\
& \beta_{2} \operatorname{Ln} \beta_{x 2}+\beta_{3} \operatorname{Ln} \beta_{x 3}+u i
\end{aligned}
$$

Keterangan :

$$
\begin{aligned}
\mathrm{Y}= & \text { pendapatan pedagang UMKM } \\
& \text { Makanan di sekitar Mall } \\
& \text { Dinoyo City } \\
\beta_{0}= & \text { Konstanta } \\
\mathrm{X} 1= & \text { Modal } \\
\mathrm{X} 2= & \text { Jam Dagang } \\
\mathrm{X} 3= & \text { Lokasi berdagang }
\end{aligned}
$$

$\beta_{1} \beta_{2} \beta_{3}=$ Variabel yang dicari untuk mengukur elastisitas hasil terhadap variabel X1,X2,X3.

PEMBAHASAN

\section{Deskripsi Karakteristik responden}

Responden dalam penelitian ini adalah 60 pedagang mikro makanan dan minuman di sekitar Mall Dinoyo City. Karakteristik responden dalam penelitian ini meliputi :

\section{a. Umur Pedagang}

Deskripsi pedagang sampel menurut umur dapat dilihat pada Tabel 1 berikut ini :

Tabel 1. Deskripsi Umur Pedagang

\begin{tabular}{cccr}
\hline No & $\begin{array}{c}\text { Rentang } \\
\text { Umur }\end{array}$ & F & Persentase \\
\hline 1 & $24-28$ & 8 & $13,33 \%$ \\
\hline 2 & $29-33$ & 13 & $21,67 \%$ \\
\hline 3 & $34-39$ & 12 & $20 \%$ \\
\hline 4 & $40-44$ & 8 & $13,33 \%$ \\
\hline 5 & $45-49$ & 9 & $15 \%$ \\
\hline 6 & $50-54$ & 4 & $6,67 \%$ \\
\hline 7 & $55-60$ & 4 & $6,67 \%$ \\
\hline 8 & $60-65$ & 2 & $3,33 \%$ \\
\hline & Jumlah & 60 & $100 \%$ \\
\hline
\end{tabular}

Sumber: data primer diolah, 2016

Berdasarkan Tabel 1 diketahui bahwa umur pedagang sampel pada kelompok umur lebih dari 61 tahun sebesar 3,33\%, pada kelompok umur 
Analisis Pendapatan Pedagang Mikro Makanan dan Minuman...(Wahyu Dwi N)

24-28 tahun sebesar 13,33\%.Pada kelompok umur 29-33 tahun sebesar 21,67\%. pada kelompok umur 34-39 tahun sebesar 20\%.Pada kelompok umur 40-44 tahun sebesar 13,33\%. Kelompok umur 45-49 tahun sebesar 15\%. Kelompok umur 50-54 tahun sebesar 6,67\%. Kelompok umur 5560tahun bahwa kebanyakkan umur pedagang sampel berada pada kelompok umur usia produktif.

\section{b. Pendidikan Pedagang}

Berdasarkan Tabel 2 dapat diketahui bahwa pendidikan pedagang yang lulus SD sebesar 13,33\%, SMP , 16,67\%, SMA 68,33\%. Dan Diploma 1,67\%.

Tabel 2. Deskripsi

TingkatPendidikan

Terakhir Pedagang

\begin{tabular}{clcl}
\hline No & $\begin{array}{c}\text { Pendidikan } \\
\text { Terakhir }\end{array}$ & F & Persentase \\
\hline 1 & SD & 8 & $13,33 \%$ \\
\hline 2 & SMP & 10 & $16,67 \%$ \\
\hline 3 & SMA & 41 & $68,33 \%$ \\
\hline 4 & DIPLOMA & 1 & $1,67 \%$ \\
\hline & Jumlah & 60 & $100 \%$
\end{tabular}

Sumber: data primer diolah, 2016
Hal ini menunjukkan bahwa tingkat pendidikan cukup tinggi. Tingginya pendidikan inilah yang mendorong seseorang untuk bekerja pada sektor pedagangan, yang diperlukan ketrampilan berdagang.

\section{c. Jenis Kelamin Pedagang}

Berdasarkan tabel 3 diketahui bahwa pedagang yang berjenis kelamin laki-laki sebesar 25 orang atau $41,67 \%$ lebih sedikit dibandingkan dengan jenis kelamin perempuan sebesar 35 orang atau $58,33 \%$.

Tabel 3. Deskripsi Jenis Kelamin Pedagang

\begin{tabular}{cccc}
\hline No & $\begin{array}{c}\text { Jenis } \\
\text { Kelamin }\end{array}$ & F & Persentase \\
\hline $\mathbf{1}$ & Laki-Laki & 25 & $41,67 \%$ \\
\hline $\mathbf{2}$ & Wanita & 35 & $58,33 \%$ \\
& & & \\
\hline & Jumlah & 50 & $100 \%$
\end{tabular}

Sumber: data primer diolah, 2016

\section{d. Modal Pedagang}

Berdasarkan table 4 di atas Sebanyak $(66,67 \%)$ berpendapat 
modal berdagang pedagang berasal dari dana sendiri dan Sebanyak $(33,33 \%)$ berpendapat bahwa modal berdagang pedagang berasal dari dana pinjaman dan gunakan untuk pengadaan sarana dan prasarana lain.

Tabel 4. Deskripsi Modal Pedagang

\begin{tabular}{lllll}
\hline No & Skor & $\begin{array}{c}\text { Keterang } \\
\text { an }\end{array}$ & F & $\begin{array}{c}\text { Persen } \\
\text { tase }\end{array}$ \\
\hline 1 & $3-4$ & Tidak & 20 & $33,33 \%$ \\
\hline 2 & $5-6$ & Ya & 40 & $66,67 \%$ \\
\hline & & Jumlah & 60 & $100 \%$
\end{tabular}

Sumber: data primer diolah, 2016

\section{e. Jam Dagang}

Damayanti (2011) menemukan bahwa semakin banyak jam kerja yang digunakan oleh pedagang untuk berjualan maka semakin besar peluang untuk mendapatkan pendapatan yang besar pula.

Adanya hubungan langsung antara jam kerja dengan tingkat pendapatan. Setiap penambahan waktu operasi akan makin membuka peluangbagi bagi bertambahnya omzet penjualan.
Setiap penambahan waktu operasi akan makin membuka peluang bagi bagi bertambahnya omzet penjualan (Firdausa,2013).

Tabel 5. Deskripsi Jam

DagangPedagang

\begin{tabular}{llllr}
\hline No & Skor & Kategori & F & $\begin{array}{c}\text { Persen } \\
\text { tase }\end{array}$ \\
\hline 1 & $4-7$ & Tidak & 0 & $0 \%$ \\
\hline 2 & $8-10$ & $\begin{array}{l}\text { Kadang- } \\
\text { kadang }\end{array}$ & 2 & $3,33 \%$ \\
\hline 3 & $11-13$ & Sering & 9 & $15 \%$ \\
\hline 4 & $14-16$ & Selalu & 49 & $81,67 \%$ \\
\hline & & jumlah & 60 & $100 \%$
\end{tabular}

Sumber: data primer diolah, 2016

Berdasarkan table 5 di atas dapat diketahui diperoleh keterangan Sebanyak $(81,67 \%)$ berpendapat bahwa pedagang selalu berdagang di sekitar Mall Dinoyo City. Sebanyak (15\%) berpendapat bahwa pedagang sering berdagang sekitar Mall Dinoyo City. Sebanyak $(3,33 \%)$ berpendapat bahwa pedagang kadang-kadang berdagang di sekitar Mall Dinoyo City.

\section{f. Lokasi}


Penentuan lokasi usaha merupakan hal yang penting dalam mendirikan suatu usaha. Karena semakin strategis lokasi dari usaha tersebut maka semakin memberikan dampak yang baik untuk perusahaan seperti menambah pendapatan perusahaan, menambah konsumen perusahaan (Herdyanti ,2013)

Berdasarkan tabel 6 di atas dapat diketahui Sebanyak (40\%) berpendapat bahwa lokasi berdagang di sekitar Mall Dinoyo City sangat baik. Dan sebanyak $(60 \%)$ berpendapat bahwa lokasi berdagang di sekitar Mall Dinoyo City baik.

\section{Tabel 6. Deskripsi Lokasi Berdagang}

\begin{tabular}{lllcr}
\hline No & Skor & Kategori & F & $\begin{array}{c}\text { Persent } \\
\text { ase }\end{array}$ \\
\hline 1 & $5-8$ & $\begin{array}{l}\text { Sangat } \\
\text { Tidak Baik }\end{array}$ & 0 & $0 \%$ \\
\hline 2 & $9-12$ & Tidak Baik & 0 & $0 \%$ \\
\hline 3 & $13-16$ & Baik & 36 & $60 \%$ \\
\hline 4 & $17-20$ & Sangat Baik & 24 & $40 \%$ \\
\hline & & Jumlah & $\mathbf{6 0}$ & $\mathbf{1 0 0 \%}$
\end{tabular}

Sumber: data primer diolah, 2016

\section{g. Pendapatan}

Berdasarkan tabel 7 dapat diperoleh keterangan sebagai berikut, Sebanyak $(23,33 \%)$ berpendapat bahwa pendapatan berdagang di sekitar Mall Dinoyo City meningkat.

$$
\text { Sebanyak }
$$

berpendapat bahwa pendapatan berdagang di sekitar Mall Dinoyo City Tetap , tidak mengalamai peningkatan ataupun tidak mengalami penurunan.

Tabel 7. Deskripsi Pendapatan

Pedagang

\begin{tabular}{|c|c|c|c|c|}
\hline No & Skor & Kategori & $\mathrm{F}$ & $\begin{array}{c}\text { Persen } \\
\text { tase }\end{array}$ \\
\hline 1 & $3-4$ & Menurun & 0 & $0 \%$ \\
\hline 2 & $5-6$ & Tetap & 46 & $76,67 \%$ \\
\hline 3 & $7-9$ & Meningkat & 14 & $23,33 \%$ \\
\hline \multirow[t]{2}{*}{4} & $10-12$ & $\begin{array}{l}\text { Sangat } \\
\text { Meningkat }\end{array}$ & 0 & $0 \%$ \\
\hline & & jumlah & 60 & $100 \%$ \\
\hline
\end{tabular}

Sumber: data primer diolah, 2016

\section{Analisis Data}

\section{a. Uji Normalitas Data}

Uji normalitas data bertujuan untuk menguji apakah dalam model 
regresi, variabel independen dan dependen mempunyai distribusi normal atau tidak. Model regresi yang baik adalah distribusi data normal atau mendekati normal. Alat analisis yang dapat digunakan adalah dengan melihat tampilan plot atau data dapat juga menggunakan uji kolmogrov smirnov (Ghozali, 2009:147).

\section{Gambar 1. Diagram Uji Normalitas}

\section{Data}

Normal P-P Plot of Regression Standardized Residual

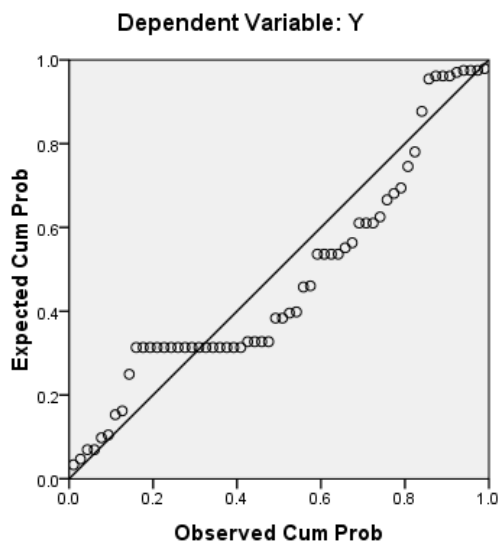

Sumber: data primer diolah, 2016
Dari analisis kurva dapat dilihat bahwa data menyebar di sekitar diagram dan mengikuti model regresi sehingga dapat disimpulkan bahwa data yang diolah merupakan data yang berdistribusi normal sehingga uji normalitas terpenuhi.

\section{b. Uji Multikolinieritas Data}

Pengujian adanya multikolinier ini dapat dilakukan dengan melihat nilai VIF (varians inflation factor) pada masing-masing variabel bebasnya. Jika nilai VIFnya lebih kecil dari 10 tidak ada kecenderungan terjadi gejala multikolinier.

Hasil perhitungan pada tabel 8 menunjukkan bahwa modal mempunyai nilai tolerance 0,953 dan VIF 1.050; jam dagang mempunyai nilai tolerance 0,939 dan VIF 1.065.

Pada Variabel okasi mempunyai nilai tolerance 0,931 dan VIF 1.074 Sehingga nilai dari masing-masing variabel menunjukkan bahwa nilai tolerance lebih dari 0,1 dan nilai VIF kurang dari 10. Jadi dapat disimpulkan bahwa tidak ada 
Analisis Pendapatan Pedagang Mikro Makanan dan Minuman...(Wahyu Dwi N)

multikolonieritas antar variabel pendapatan (Y) digunakan analisis independen dalam model regresi.

regresi berganda.

Hasil analisis regresi berganda pada tabel 9 diperoleh koefisien untuk variabel bebas $\mathrm{X} 1=0,580, \mathrm{X} 2=$ $0,191, \mathrm{X} 3=0,271$ dengan konstanta

Tabel 8. Uji Multikolinier Data

\begin{tabular}{llcc}
\hline & & Tolerance & VIF \\
\hline 1 & (Constant) & \\
\cline { 2 - 3 } & & & \\
\hline $\mathrm{x} 1$ & .953 & 1.050 \\
\hline $\mathrm{x} 2$ & .939 & 1.065 \\
& & \\
\hline $\mathrm{x} 3$ & .931 & 1.074 \\
\hline
\end{tabular}

Sumber: data primer diolah, 2016

\section{c. Analisis Regresi Linear}

\section{Berganda}

Berdasarkan hasil analisis regresi berganda yang dilakukan dengan bantuan program SPSS versi 16.00 yaitu antara nilai modal (X1), jam dagang (X2), dan lokasi (X3), dan sebesar $-2,958$ sehingga model persamaan regresi yang diperoleh adalah:

$\mathrm{Y}=-2,958+0,580 \mathrm{X} 1+0,191 \mathrm{X} 2+$

$0,271 \times 3$

Model regresi tersebut mengandung arti :

1) Nilai konstan (Y) sebesar $-2,958$ yang berarti bahwa jika modal, jam dagang dan lokasi sama dengan nol maka pendapatan akan mengalami peningkatan $-2,958$.

\section{Tabel 9. Analisis Regresi Linear Berganda}

Coefficients $^{\mathrm{a}}$

Standardized

Coefficients 


\section{Coefficients}

\begin{tabular}{|c|c|c|c|c|c|c|}
\hline \multicolumn{2}{|c|}{ Model } & \multirow{3}{*}{$\begin{array}{l}\text { B } \\
-2.958\end{array}$} & \multirow{3}{*}{$\begin{array}{r}\text { Std. Error } \\
2.406\end{array}$} & \multirow[b]{2}{*}{ Beta } & \multirow[t]{2}{*}{$\mathrm{T}$} & \multirow{2}{*}{ Sig. } \\
\hline & & & & & & \\
\hline \multirow[t]{4}{*}{1} & (Constant) & & & & -1.230 & .224 \\
\hline & $\mathrm{x} 1$ & .580 & .243 & .288 & 2.383 & .021 \\
\hline & $\mathrm{x} 2$ & .191 & .135 & .172 & 1.413 & .163 \\
\hline & x3 & .271 & .102 & .325 & 2.660 & .010 \\
\hline
\end{tabular}

a. Dependent Variable: Y

2) Koefisien regresi $X 1$ (modal) dari perhitungan linier berganda didapat nilai koefisien $(\mathrm{b} 1)=$ 0,580. Variabel $\quad \mathrm{X} 1 \quad$ (Modal) berpengaruh positif terhadap pendapatan.

3) Koefisien regresi $X 2$ (jam dagang) dari perhitungan linier berganda didapat nilai koefisien (b2) 0,191.Variabel X2 (Jam dagang berpengaruh positif terhadap pendapatan, namun tidak signifikan.

Koefisien regresi X3 (lokasi) dari perhitungan linier berganda didapat nilai koefisien (b3) = 0,271.Variabel X3 (Lokasi) berpengaruh positif dan signifikan.

\section{d. Uji Hipotesis Parsial (Uji t)}

Uji hipotesis dilakukan untuk mengetahui ada tidaknya pengaruh variabel bebas dengan variabel terikat baik secara parsial. Hasil analisis uji hipotesis antara variabel bebas X1, $\mathrm{X}$ 2, dan $\mathrm{X} 3$ terhadap $\mathrm{Y}$ diperoleh hasil sebagai berikut.

\section{a) Pengujian Hipotesis 1 (H1) dengan uji t atau uji parsial}

Dalam tabel 10 menunjukan bahwa koefisien korelasi secara parsial untuk variabel modal sebesar 0,580. Uji keberartian koefisien korelasi untuk hasil $\mathrm{t}$ hitung sebesar 2,383 dengan probabilitas sebesar 0,021. Nilai probabilitas lebih kecil 
Analisis Pendapatan Pedagang Mikro Makanan dan Minuman...(Wahyu Dwi N)

dari pada $0,05(0,021<0,05)$ maka diterima.

dengan demikian Ho ditolak dan $\mathrm{Ha}$

Tabel 10. Uji Hipotesis Parsial (t)

Coefficients $^{\mathrm{a}}$

Standardized

Coefficients

\begin{tabular}{|c|c|c|c|c|c|c|c|c|}
\hline & \multirow{2}{*}{ Model } & \multicolumn{3}{|c|}{$\begin{array}{c}\text { Unstandardized } \\
\text { Coefficients }\end{array}$} & \multirow[t]{2}{*}{$\mathrm{T}$} & \multirow[t]{2}{*}{ Sig. } & \multicolumn{2}{|c|}{$\begin{array}{l}\text { Collinearity } \\
\text { Statistics }\end{array}$} \\
\hline & & B & $\begin{array}{l}\text { Std. } \\
\text { Error }\end{array}$ & Beta & & & $\begin{array}{l}\text { Tolera } \\
\text { nce }\end{array}$ & VIF \\
\hline 1 & constant & -2.958 & 2.406 & & -1.230 & .224 & & \\
\hline & $\mathrm{X} 1$ & .580 & .243 & .288 & 2.383 & .021 & .953 & 1.050 \\
\hline & $\mathrm{X} 2$ & .191 & .135 & .172 & 1.413 & .163 & .939 & 1.065 \\
\hline & X3 & .271 & .102 & .325 & 2.660 & .010 & .931 & 1.074 \\
\hline
\end{tabular}

a.Dependent Variable : Y

Sumber: data primer diolah, 2016

Maka menunjukan bahwa nilai $\mathrm{t}$ yang diperoleh tersebut signifikan. Sehingga hipotesis 1 (H1) yang diuji dalam penelitian ini yaitu " modal berpengaruh terhadap pendapatan pedagang mikro makanan dan minuman di sekitar Mall Dinoyo City" diterima. Kontribusi modal terhadap pendapatan pedagang kecil sekitar Mall Dinoyo City $\left(\mathrm{r}^{2}\right)$ adalah $(0.953)^{2} \times 100 \%=91 \%$.

\section{b) Pengujian Hipotesis 2 (H2) uji t atau uji parsial}

Berdasarkan hasil penelitian seperti yang terangkum dalam tabel di atas menunjukkan bahwa koefisien 
korelasi secara parsial untuk variabel jam dagang sebesar 0,191.

Uji keberartian koefisien korelasi untuk hasil t hitung sebesar 1,413 dengan probabilitas sebesar 0,163 . Nilai probabilitas lebih besar dari pada $0,05(0,163>0,05)$ maka dengan demikian $\mathrm{Ha}$ ditolak menerima Ho.

Maka menunjukan bahwa nilai $\mathrm{t}$ yang diperoleh tersebut tidak signifikan. Sehingga hipotesis 2 (H2) yang diuji dalam penelitian ini yaitu" jam dagang berpengaruh terhadap pendapatan pedagang kecil sekitar Mall Dinoyo City” ditolak.

\section{c) Pengujian Hipotesis 3 (H3) uji t atau uji parsial}

Seperti yang terangkum dalam tabel di atas menunjukan bahwa koefisien korelasi secara parsial untuk variabel lokasi sebesar 0,271. Uji keberartian koefisien korelasi untuk hasil t hitung sebesar 2,660, dengan probabilitas sebesar 0,010 .

Nilai probabilitas tersebut lebih kecil dari pada $0,05(0,010<0,05)$ dengan demikian Ho ditolak dan menerima $\mathrm{Ha}$, maka dengan demikian Ho ditolak menerima $\mathrm{Ha}$ maka menunjukan bahwa nilai $\mathrm{t}$ yang diperoleh tersebut signifikan.

Sehingga hipotesis 3 (H3) yang diuji dalam penelitian ini yaitu "lokasi berpengaruh terhadap pendapatan pedagang kecil di sekitar Mall Dinoyo City” diterima. Kontribusi lokasi terhadap pendapatan pedagang mikro makanan dan minuman di sekitar Mall Dinoyo City $\left(\mathrm{r}^{2}\right)$ adalah $(0,931)^{2} \times 100 \%=87$ $\%$.

\section{e. Uji Hipotesis Secara Simultan (Uji F)}

Uji statistik $F$ pada dasarnya menunjukkan apakah semua variabel bebas yang dimasukkan dalam model mempunyai pengaruh secara bersamasama terhadap variabel terikat (Ghozali, 2009:88).

Hasil pengujian pada tabel di atas, uji simultan (uji F) menunjukkan bahwa nilai Ftabel didapat dari df1 = 3 dan df $2=56$ dengan alpha $=0,05$ artinya kita mengambil risiko salah 
Analisis Pendapatan Pedagang Mikro Makanan dan Minuman...(Wahyu Dwi N)

dalam mengambil keputusan untuk

menolak hipotesis yang benar

sebanyak-banyaknya $5 \%$.

Tabel 11. Uji Simultan (Uji f)

\begin{tabular}{|c|c|c|c|c|c|c|}
\hline \multicolumn{7}{|c|}{ ANOVA $^{\mathrm{b}}$} \\
\hline & Model & $\begin{array}{l}\text { Sum of } \\
\text { Square }\end{array}$ & $\mathrm{df}$ & Mean Square & $\mathrm{F}$ & Sig. \\
\hline \multirow[t]{3}{*}{1} & Regresion & 16.256 & 3 & 5.419 & 5.349 & $.003^{\mathrm{a}}$ \\
\hline & Residual & 56.727 & 56 & 1.013 & & \\
\hline & Total & 72.938 & 56 & & & \\
\hline & 1. Predicto & $\tan t), x 3, x$ & & & & \\
\hline & Depenc & iable : Y & & & & \\
\hline
\end{tabular}

Tabel 11 menunjukkan bahwa diperoleh nilai Fhitung sebesar 5,349 dikarenakan nilai Fhitung $(5,349)>$ Ftabel (2,77) atau besarnya probabilitas sebesar $0,003<0,05$. Dengan demikian, dalam penelitian ini menyatakan bahwa ada pengaruh yang signifikan dari modal, jam dagang dan lokasi sebagai variabel bebas secara simultan (bersama-sama) terhadap pendapatan pedagang sebagai variabel terikat.

\section{f. Koefisien Determinsi}

Analisis ini dilakukan untuk mengetahui seberapa besar nilai prosentase kontribusi variabel bebas terhadap variabel terikat. Dalam out put SPSS, koefisien determinasi terletak pada table Model Summary dan tertulis $R$ square sebagai berikut.

Tabel 12. Uji Koefisien Determinasi Secara Bersama-Sama 


\begin{tabular}{|c|c|c|c|c|c|}
\hline \multicolumn{6}{|c|}{ Model Summary ${ }^{b}$} \\
\hline Model & $\mathrm{R}$ & $\begin{array}{l}\mathrm{R} \\
\text { Square }\end{array}$ & $\begin{array}{l}\text { Adjusted R } \\
\text { Square }\end{array}$ & $\begin{array}{l}\text { Std. Error } \\
\text { of the } \\
\text { Estimate }\end{array}$ & $\begin{array}{l}\text { Durbin- } \\
\text { Watson }\end{array}$ \\
\hline 1 & $.472^{\mathrm{a}}$ & .223 & .181 & 1.00647 & 1.849 \\
\hline a. & \multicolumn{5}{|c|}{ Predictors : (constant), x3,x1,x2 } \\
\hline
\end{tabular}

Dari hasil perhitungan statistik dapat diketahui bahwa nilai Adjusted $R$ Square sebesar 0,181, hal itu berarti bahwa variasi perubahan $\mathrm{Y}$ dipengaruhi oleh perubahan $\mathrm{X} 1, \mathrm{X} 2$, dan X3 sebesar 18,1\%, sedangkan sisanya dipengaruhi variabel yang ada diluar model sebesar $81.9 \%$.

\section{PENUTUP}

Berdasarkan hasil penelitian dan pembahasan, maka dapat disimpulkan sebagai berikut :

Penelitian pada kelompok umur pedagang pada kelompok umur 29-33 tahun adalah yang paling tinggi yaitu sebesar $21,67 \%$.

Pada tingkat pendidikan responden, pendidikan SMA yang paling tinggi yaitu sebesar
68,33\%.. Karakteristik jenis kelamin responden, bahwa pedagang yang berjenis kelamin laki-laki sebesar $41,67 \%$ lebih sedikit dibandingkan dengan jenis kelamin perempuan sebesar $58,33 \%$.

Modal berpengaruh terhadap pendapatan pedagang mikro makanan dan minuman di sekitar Mall Dinoyo City. X1 (Modal) berpengaruh positif terhadap pendapatan. Dengan modal yang besar tersebut pedagang memiliki fasilitas usaha yang tentu lebih bagus dan menunjang operasional usahanya dengan baik sehingga konsumen tertarik untuk membeli dagangan sehingga permintaan akan barang atau jasa lebih banyak. Dengan demikian, pedagang dengan modal besar bisa memiliki pendapatan yang lebih besar daripada yang memiliki modal kecil. 
Jam dagang tidak berpengaruh terhadap pendapatan pedagang mikro makanan dan minuman di sekitar Mall Dinoyo City. Variabel X2 (Jam dagang berpengaruh positif terhadap pendapatan, namun tidak signifikan. Jika jam dagang panjang namun produk yang dijual tidak dapat menarik banyak konsumen maka pendapatan akan sama saja, lain dengan jam kerja pendek namun produk yang dijual menarik konsumen maka pendapatan akan meningkat meskipun jam dagang yang pendek.

Lokasi berpengaruh terhadap pendapatan pedagang mikro makanan dan minuman di sekitar Mall Dinoyo City. Lokasi usaha yang strategis akan mudah terlihat oleh konsumen, sehingga akan banyak konsumen yang berdatangan. Meningkatnya jumlah pelanggan akan berakibat pada peningkatan laba bersih usaha. Jarak dengan pemukiman masyarakat yang diperkirakan akan berkunjung sebaiknya juga tidak terlalu jauh, dan untuk mencapainya tersedia cukup fasilitas transportasi atau aksesibilitas yang lancar.

Hal ini menjadikan jarak yang jauh dirasakan menjadi lebih dekat yaitu adanya jalan dan alat transportasi, kemudahan untuk parkir, kelengkapan dan kualitas barangbarang yang dijual dan kemudahan untuk mencapai lokasi (tidak macet misalnya)

Modal, Jam Dagang dan Lokasi diperoleh nilai $\mathrm{F}$ hitung sebesar 5,349 $>\mathrm{F}$ tabel $(2,77)$ dengan besar probabilitas $0,003<0,05$. Dengan demikian dalam penelitian ini ada pengaruh signifikan dari Modal, Jam Dagang dan Lokasi terhadap pendapatan pedagang mikro makanan dan minuman di sekitar Mall Dinoyo City.

\section{Saran}

Berdasarkan hasil penelitian yang dilaksanakan pada pedagang mikro makanan dan minuman di sekitar Mall Dinoyo City maka dapat diberikan saran-saran sebagai berikut: 
Secara khusus, bagi pedagang hendaknya melakukan menambah modal sehingga kebutuhan untuk perdagangan dapat dipenuhi agar dapat mendapatkan keuntungan lebih banyak.

Dalam menentukan $\begin{array}{r}\text { lokasi } \\ \text { berdagang }\end{array}$ seharusnya
pedagang
keadaan, letak yang dekat dengan
konsumen dan yang jauh dengan
konsumen harus memberikan
pelayanan yang lebih baik.

Para pemerintah hendaknya membantu para pedagang mikro makanan dan minuman dalam mencari modal atau dana awal agar para pedagang dapat memperbaiki produk dagangannya.

\section{DAFTAR PUSTAKA}

Bambang Riyanto. 2001, Dasar-dasar Pembelanjaan

Perusahaan.Yogyakarta:

Yayasan Badan Penerbit Gadjah Mada.
Boediono. 1999, Pengantar Ekonomi Mikro, Raja Grafindo Persada, Jakarta.

D, James, Stice., K, Earl, Stice., dan Fred, K. Skousen. 2001,Akuntansi Keuangan Menengah, edisi pertama, Salemba Empat. Jakarta.

Damayanti, I. 2011, Analisis FaktorFaktor Yang Mempengaruhi Pendapatan Pedagang Kaki Lima di Pasar Gede Kota Surakarta.

http://core.ac.uk/download/pdf/ 12348858.pdf. Diunduh 12 Februari 2016.

Firdausa, Rosetyadi .2013, Jurnal Penelitian Pengaruh Modal Awal, Lama Usaha, dan Jam Kerja Terhadap Pendapatan Pedagang Kios di Pasar Bintoro Demak .

Ghozali, Imam. 2009, Aplikasi Analisis Multivariate Dengan Program SPSS Cetakan IV. Semarang : BP UNDIP.

Hardyanti, Ismi. 2013. Pengaruh Lokasi Usaha Terhadap Perkembangan Bisnis. https://herdyantismi.wordpress. com/2013/11/26/pengaruhlokasi-usaha-terhadap- 
Analisis Pendapatan Pedagang Mikro Makanan dan Minuman...(Wahyu Dwi N)

perkembangan-bisnis/ . Diakses 12 Maret 2016.

Kuncoro. 2007, Industri Kecil dan UMKM. Jakarta : FE UI

Nurseta ， Akhbar. 2015,Jurnal Penlitian Analisis Pengaruh Jarak , Lama Usaha , Modal dan Jam kerja Terhadap Pendapatan Pedagang kaki lima Konveksi di Kelurahan Purwodinatan Kota Semarang.

Partomo, Tiktik Sartika dan Abd Rachman Soejoedono.2004, Ekonomi Skala Kecil/Menengah danKoperasi. Bogor Selatan: Penerbit Ghalia Indonesia.

\section{Santoso, Y.N.B. 2001. Faktor-Faktor Yang Mempengaruhi Pendapatan Pedagang Kaki Lima:Studi Kasus Pedagang Kaki Lima Di Jalan Gejayan Dan Jalan MalioboroYogyakarta.http:// www.library.usd.ac.id/.Diun duh 14 Februari 2016}

Sitepu, Rosidin Karo-Karo, Dampak Keberadaan Pasar Modern Terhadap Kinerja Ekonomi Regional, QE Journal, Vol.01 - No.01, T.Th,.

Sugiharsono, dkk., 2008, Contextual

Teaching and Learning Ilmu
Pengetahuan Sosial: Sekolah Menengah

Pertama/Madrasah

Tsanawiyah Kelas VIII Edisi 4, Jakarta : Pusat Perbukuan Departemen Pendidikan Nasional.

Tambunan, Tulus. 2012, Usaha Kecil dan Menengah Di Indonesia . Jakarta: PT Salemba Emban Patria.

Wicaksono, Dedy (2011). Jurnal Penelitian Analisis FaktorFaktor Yang Mempengaruhi Pendagang Kaki Lima Penjual Bakso di Kota Semarang 
Jurnal Ekonomi Pembangunan, Vol. 2, No. 2, Juli 2016 